\title{
Balance in Life and Declining Marginal Utility of Diverse Resources
}

\author{
Ed Diener • Weiting Ng • Will Tov
}

Received: 9 April 2009 / Accepted: 16 April 2009/

Published online: 30 April 2009

(C) Springer Science + Business Media B.V./

The International Society for Quality-of-Life Studies (ISQOLS) 2009

\begin{abstract}
Declining marginal utility (DMU) describes the reduced value that additional units of money or consumer goods have in comparison to units acquired earlier. We extend this idea to social resources and activities such as socializing time, free time, and number of children, suggesting that most resources will show DMU as the person experiences more of them. In Study 1, participants reported how many years of adult life they would sacrifice to have increasingly more of each resource or activity. Income showed declining marginal utility, but other goods showed an ideallevel pattern in which they were valued less after an optimal amount. In Phase 2 of Study 1, we assessed the mix of activities people most prefer. Participants rated the desirability of various combinations of time spent in different activities. Spending all of one's free time in a pleasant activity was not as desirable as spending some of the time in other desirable, but less enjoyable, activities. In Study 2, we used a representative sample of the world to assess people's affect balance (positive minus negative moods) on the previous day, along with how much time they spent in activities such as socializing with family and friends. The most popular activity was socializing with family and friends, but even here there was DMU for more hours of this behavior. We also analyzed several forms of well-being in reference to household income. Income showed a clear DMU pattern using daily moods as the outcome, as well as for life evaluations and satisfaction with standard of living. The results of the two studies explain why people do not pursue happiness by spending all of their time in the most pleasant activities, such as socializing, but instead choose a mixture of activities. A desire for balance in human activities and resources
\end{abstract}

E. Diener $(\square)$

Department of Psychology, University of Illinois, 603 E. Daniel Street, Champaign, IL 61820, USA

e-mail: ediener@uiuc.edu

W. Ng

Singapore Institute of Management, Singapore, Singapore

W. Tov

Singapore Management University, Singapore, Singapore 
has important implications for the structure of the workplace, leisure time, work hours, and other important domains of life.

Keywords Well-being $\cdot$ Happiness $\cdot$ Declining marginal utility $\cdot$ Balance . Life satisfaction

Economists maintain that there is declining marginal utility (DMU) for money and other goods - the more one possesses of them, the less each additional unit is valued. In terms of subjective well-being, the idea of DMU suggests that the more income one has, the less additional income will benefit a person's happiness. Stated another way, the more income one has, the more income is required to raise one's happiness a given amount. This pattern has been found in a number of studies on subjective well-being (e.g., Diener and Biswas-Diener 2002), and has led to the recommendation that people in economically developed nations spend less time on the production and consumption of market goods, and more time in other activities such as socializing and leisure (e.g., Layard 2005). The economist Gary Becker (1965) suggested that people allocate their time between various activities in order to maximize "utility," and that as income rises, leisure activities become more costly because of the greater income that is foregone when people do not work.

Kahneman et al. (2004) suggested that people can enhance their experience of utility by reallocating their time use from less-preferred to more-preferred activities. Rather than changing the circumstances of their lives such as wealth, people might find a quicker route to happiness if they moved more of their time from activities they do not enjoy, such as commuting, to activities they enjoy more, such as socializing. Lyubomirsky (2007) echoes this sentiment in suggesting that a major way people can increase their happiness is to move time from less rewarding to more rewarding activities. It makes sense, for example, that if we spend time making money beyond the point at which it is rewarding, happiness might be increased by switching one's activities to more enjoyable pursuits. We suggest that people must consider DMU of activities, not just money, in making decisions about how to reallocate their time. The approach of Kahneman et al. and Lyubomirsky to increasing happiness will be most effective if people not only switch to more pleasant activities, but move to activities that are inherently enjoyable and not yet suffering from substantial DMU. Other goods and resources, not just money, might also show a pattern of DMU, and this must be considered when allocating time to activities. In essence, we are suggesting that people should find life balance, as suggested by Sirgy and Wu (2009), that includes a mix of activities. The best balance will come from a joint consideration of how rewarding activities are for the person and where the person is on the curve of declining marginal utility for each activity.

The concept of DMU of activities can be illustrated with sex. Although hedonists such as Hugh Hefner, the founder of Playboy magazine and an advocate of a hedonistic lifestyle, might suggest that we spend most of our waking time having sex, none of us pursue this course. Although "intimate relationships" can be the most pleasant time of one's day (Kahneman et al. 2004), many individuals with a lot of money and free time do not spend it all having sex. Various surveys suggest that the average adult American has sex only 62 to 85 times per year (Cartwright 2007; James 1998, as cited in Smith 2006), which is certainly much less than the free time available would 
permit. Why don't people spend more time involved in sexual activity? There are constraints on people's time, such as responsibilities and obligations, which prevent them from having sex during all of their free time. However, most people choose to spend the vast majority of their discretionary free time in activities other than sex, such as talking on the phone, that although pleasurable, are not as pleasurable as sex. How can this be, if we are motivated by hedonic concerns?

Perhaps people do not have sex continually because they recognize that most or all activities have DMU when it comes to happiness and pleasure, and that the most happiness can be derived from spreading one's time across a mix of pleasant activities. In this way, people can maximize pleasure by involvement in fresh activities in which DMU is low. The theoretical reason for DMU offered by economists is that the first units of a good are more desirable because the individual will obtain the most-needed outcome with the first amount of resource, and later will use the resource for outcomes that are not quite as desirable as those chosen first. For example, when a person obtains free time they will use the initial time for highly desirable activities that they most desire, and will use excess free hours for activities that are not as desirable. This theory suggests steadily declining utility of the resource as the person obtains more of it.

In this research we analyzed the issue of DMU for social and leisure activities in addition to income, as well as the desirability of a balance among them. We address two related questions: do other activities and goods besides money show DMU, and do people prefer a mix of activities rather than spending all of their time in a favored activity? If even activities such as socializing and leisure pursuits show DMU, this suggests that a balance of them is probably needed to achieve the maximum happiness.

In the first study we explored DMU across a variety of domains and resources. We used a method that involved asking respondents how many life-years they would give up to live a shorter time with greater amounts of a particular resource or activity. For example, if one were to live to age 90 without having any social time, how many life-years would one sacrifice to instead have specified amounts of social time each day? For example, how many life-years would one sacrifice to have 30 (or 60 or 120) minutes of socializing time per day instead of none?

In Phase 1 of this study, we asked about increasing amounts of income and also inquired about increasing amounts of activities such as socializing and watching television and movies. We also inquired about the value of having increasing amounts of children and athletic ability. Thus, we examined DMU in diverse activities and resources. Our hypothesis was that most or all goods show DMU, indicated by the fact that respondents will give up fewer life-years to obtain additional units of them. In Phase 2 of the study, we presented several sets of mixed activities to our participants and asked them how desirable they considered each combination to be. This allowed us to determine whether a set of activities that is overwhelmingly composed of a very popular activity (e.g., socializing) is seen as more rewarding than one that contains a more balanced mix of activities, including some that are desirable, but less so than the favored activity. In other words, do people believe they can maximize their happiness by spending all of their time in a heavily favored activity, or by balancing their time with other activities? Strong evidence that people perceive DMU even in activities such as socializing will be obtained if participants both will give decreasing numbers of life years for additional units of it, and also do not want all of their time in their most favored activity, instead desiring a mix that includes less preferred activities. 
In Study 2 we analyzed actual time spent in several daily activities, as well as income, in relation to affect during the day. In this study we used a representative survey of the world and analyzed the utility associated with free time, time with family and friends, income, and the disutility of commuting time. The times spent in activities were those from the previous day, and were not hypothetical amounts as in Study 1. Furthermore, measured feelings (positive minus negative) were used to assess utility, not hypothetical life years. Therefore, the methods used to test DMU were more ecologically valid that those employed in Study 1. Study 2 also extended previous findings by examining feelings in addition to judgments of life. Study 1 had the advantage of controlling individual differences in selection across the various levels of the activities. In other words, Study 1 did not allow for the alternate explanation to DMU that people with different levels of happiness chose to spend their time in different ways, and therefore that personality differences were responsible for the outcomes.

\section{Study 1}

Study 1 Methods, Phase 1

Undergraduates ( $N=180 ; 127$ females; 52 males; one person did not indicate gender) from the University of Illinois completed the survey as part of a class exercise for extra credit. All students gave their permission to use their data for research purposes, although this was not required of them. The survey instructed participants to imagine living their life (from age 20 to age 90) under certain conditions. Other than the manipulated condition, they were asked to assume they would live the entire 70 adult years in excellent health, without any signs of old age, and then die abruptly without illness or pain when they were 90 years old.

The valued goods we varied were income, time spent relaxing with family/friends (social time), time spent watching television and movies (TV time), number of children, and athletic skill. Each condition specified a target amount of the resource (e.g., social time) that the participants would experience throughout their entire 70 hypothetical life-years-usually zero. The variable of interest was the number of years of life that participants would be willing to sacrifice (out of 70) to increase the target by a specific amount. The more desirable participants perceived each alternative relative to the target, the greater number of life-years they should be willing to sacrifice in order to obtain the alternatives.

For each alternative amount, participants rated how short they were willing to live in order to obtain the greater amount of the resource specified in each alternative, compared to the target amount that would be experienced until age 90. Responses (from 3 to 10) were rounded off to the nearest decade, where a rating of 3 indicated that participants were willing to live to only 30 and sacrifice 60 years (the maximum possible). A rating of 10 indicated that participants would demand to live longer (to 100 years instead of the given 90) because the alternative was less desirable than the target amount, so the number of years sacrificed was-10 (the minimum possible).

The target amount for most conditions was zero, while for income the target amount was $\$ 20,000$. The first alternative was some amount of the good. Each 
successive amount was then doubled for each of four additional alternatives. For example, the target amount of social time was zero minutes. After that, five alternatives were presented: $30 \mathrm{~min}, 1 \mathrm{~h}, 2 \mathrm{~h}, 4 \mathrm{~h}$, and $8 \mathrm{~h}$. The increasing alternative amounts are shown in Table 1. Participants also indicated their gender and the average amount of time they spent each day on the Internet, on cell phone and telephone, socializing with family and friends, exercising and viewing sports, and watching television/movies and reading.

\section{Study 1 Results, Phase 1}

The mean and standard deviation of the number of life-years participants were willing to sacrifice for alternative amounts of each resource are shown in Table 1. For each resource, a repeated-measures ANOVA confirmed that there were significant differences in the number of life-years sacrificed for the different alternatives. Multiple comparisons for each resource also indicated that there was often an optimal level, where participants were willing to sacrifice the most life-years. For example, participants regarded having two children as optimal, rather than the alternative amounts. Similarly, respondents most wanted two to $4 \mathrm{~h}$ of social time on average, not more, and most preferred at least one or $2 \mathrm{~h}$ of TV/movie time per day, not more. There was even negative utility for some resources beyond a certain level (TV time and number of children). Rather than sacrificing life-years, participants demanded more before they would accept higher yet amounts of these beyond an optimum.

As can be seen in Table 1, people had different optimal levels for various resources - for income the optimal level was the highest alternative presented (640,000 US dollars per year), whereas for other resources the optimal level was at lower amounts. For income the highest amount was seen as significantly more desirable than the second-highest amount, but each successive doubling of income produced less increase in utility than the previous increase. Thus, when life years was predicted by income levels, a significant quadratic trend $(p<.001)$ beyond the linear effect emerged, due to a DMU curve.

In addition, we examined whether the actual amount of time spent on an activity (social time) affected the pattern of DMU. Those who spent more time relaxing with family and friends ( $5 \mathrm{~h}$ of more) were willing to sacrifice more life-years to obtain greater amounts of social time. Those who experienced little social time had a lower optimal level ( $2 \mathrm{~h}$ per day), and reported DMU for higher amounts. Thus, the utility desired from an activity is a joint function of individual preferences and declining marginal utility.

Additional analyses for all the conditions revealed no gender differences in the number of life-years participants would give up, with exceptions for number of children and athletic ability. Females were willing to give up significantly more lifeyears than males to have four children. Males would give up more life-years than females in order to obtain very good, excellent, or outstanding athletic skills. For these gender differences, all $t$ 's $(177)>2.54, p$ 's $<.05$.

Study 1 Methods, Phase 2

In Phase 2 participants were asked to imagine not needing to work as adults, and having $10 \mathrm{~h}$ per day to do five leisure activities. These activities were distributed 
Table 1 Mean number of life-years sacrificed for each level of each resource

\begin{tabular}{|c|c|c|c|c|c|c|c|}
\hline \multicolumn{2}{|c|}{ Resource condition } & \multirow[t]{2}{*}{$\begin{array}{l}\text { Alternative } \\
\text { amounts }\end{array}$} & \multirow{2}{*}{$\begin{array}{l}\text { Mean } \\
\text { years } \\
\text { sacrificed }\end{array}$} & \multirow[t]{2}{*}{ SD } & \multirow[t]{2}{*}{$\begin{array}{l}\text { ANOVA: } \\
\text { F-value and } p\end{array}$} & \multicolumn{2}{|c|}{$\begin{array}{l}\text { Years } \\
\text { sacrificed }\end{array}$} \\
\hline Target amount & Units & & & & & Female & Male \\
\hline \multirow{5}{*}{$\begin{array}{l}\text { Income: } 20,000 \\
\text { U.S. dollars }\end{array}$} & 1 & Income: 40,000 & $5.53_{\mathrm{a}}$ & 7.65 & \multirow{5}{*}{$\begin{array}{l}F(4,175)= \\
\quad 47.36, p<.001\end{array}$} & 5.63 & 5.19 \\
\hline & 2 & Income: 80,000 & $11.12_{\mathrm{b}}$ & 9.47 & & 10.40 & 12.88 \\
\hline & 3 & Income: 160,000 & $15.08_{\mathrm{c}}$ & 9.68 & & 14.29 & 16.92 \\
\hline & 4 & Income: 320,000 & $16.87_{\mathrm{c}}$ & 11.08 & & 16.03 & 18.85 \\
\hline & 5 & Income: 640,000 & $18.44_{\mathrm{d}}$ & 12.67 & & 17.62 & 20.19 \\
\hline \multirow[t]{5}{*}{$\begin{array}{l}\text { Social time: } \\
\text { zero }\end{array}$} & 1 & $\begin{array}{l}\text { Social time: } \\
30 \mathrm{~min}\end{array}$ & $12.67 \mathrm{a}$ & 13.64 & \multirow[t]{5}{*}{$\begin{array}{l}F(4,176)= \\
24.23, p<.001\end{array}$} & 12.36 & 13.46 \\
\hline & 2 & $\begin{array}{l}\text { Social time: } \\
60 \mathrm{~min}\end{array}$ & $15.94_{b}$ & 13.27 & & 14.96 & 18.46 \\
\hline & 3 & $\begin{array}{l}\text { Social time: } \\
120 \mathrm{~min}\end{array}$ & $21.72_{\mathrm{c}}$ & 13.36 & & 21.18 & 23.08 \\
\hline & 4 & $\begin{array}{l}\text { Social time: } \\
240 \mathrm{~min}\end{array}$ & $21.61_{\mathrm{cd}}$ & 14.92 & & 21.65 & 21.54 \\
\hline & 5 & $\begin{array}{l}\text { Social time: } \\
480 \mathrm{~min}\end{array}$ & $18.89_{\mathrm{bcd}}$ & 19.17 & & 19.13 & 18.46 \\
\hline \multirow{5}{*}{$\begin{array}{l}\text { TV \& movies } \\
\text { time: zero }\end{array}$} & 1 & TV time: $30 \mathrm{~min}$ & $4.72_{\mathrm{a}}$ & 9.65 & \multirow{5}{*}{$\begin{array}{l}F(4,176)= \\
22.64, p<.001\end{array}$} & 4.49 & 5.38 \\
\hline & 2 & TV time: $60 \mathrm{~min}$ & $6.67_{\mathrm{b}}$ & 9.86 & & 6.14 & 7.88 \\
\hline & 3 & TV time: $120 \mathrm{~min}$ & $6.56_{\mathrm{ab}}$ & 10.74 & & 6.30 & 7.12 \\
\hline & 4 & TV time: $240 \mathrm{~min}$ & $1.67_{\mathrm{c}}$ & 11.11 & & 1.65 & 1.73 \\
\hline & 5 & TV time: $480 \mathrm{~min}$ & $-1.06_{\mathrm{d}}$ & 10.86 & & -0.79 & -1.73 \\
\hline \multirow[t]{5}{*}{ No children } & 1 & Children: 1 & $18.33_{\mathrm{a}}$ & 15.12 & \multirow{5}{*}{$\begin{array}{l}F(4,175)= \\
\quad 182.04, p \\
<.001\end{array}$} & 18.90 & 16.92 \\
\hline & 2 & Children: 2 & $21.72_{b}$ & 14.68 & & 21.97 & 21.15 \\
\hline & 3 & Children: 4 & $11.83_{\mathrm{c}}$ & 16.70 & & 14.02 & 6.54 \\
\hline & 4 & Children: 8 & $-4.08_{\mathrm{d}}$ & 11.00 & & -3.73 & -5.00 \\
\hline & 5 & Children: 16 & $-6.83_{\mathrm{e}}$ & 6.89 & & -6.77 & -6.92 \\
\hline \multirow[t]{5}{*}{$\begin{array}{l}\text { Terrible athletic } \\
\text { skill }\end{array}$} & 1 & $\begin{array}{l}\text { Athletic skill: } \\
\text { Modest }\end{array}$ & $4.78_{\mathrm{a}}$ & 8.49 & \multirow[t]{5}{*}{$\begin{array}{l}F(4,176)= \\
22.74, p<.001\end{array}$} & 4.49 & 4.81 \\
\hline & 2 & $\begin{array}{l}\text { Athletic skill: } \\
\text { Good }\end{array}$ & $8.56_{b}$ & 10.20 & & 8.19 & 9.04 \\
\hline & 3 & $\begin{array}{l}\text { Athletic skill: } \\
\text { Very good }\end{array}$ & $11.50_{\mathrm{c}}$ & 12.12 & & 9.76 & 15.38 \\
\hline & 4 & Athletic skill: Excellent & $11.83_{\mathrm{cd}}$ & 14.70 & & 8.82 & 18.85 \\
\hline & 5 & $\begin{array}{l}\text { Athletic skill: } \\
\text { Outstanding }\end{array}$ & $10.06_{\mathrm{bcd}}$ & 16.63 & & 5.83 & 20.00 \\
\hline
\end{tabular}

For each resource, means with different subscripts differ a $p<.001$ with Bonferroni correction applied

across the $10 \mathrm{~h}$ in various combinations. Participants rated the desirability of each combination on a 9-point scale $(1=$ Extraordinarily undesirable; $5=$ Neutral; $9=$ Extraordinarily desirable). The five activities included: 1) Internet and games, 2) Cell phone and telephone, 3) Relaxing with family and friends, 4) Exercise and sports viewing, and 5) Watching television, movies, and reading. In three of the 
combinations all $10 \mathrm{~h}$ were allocated to a single activity (social time, Internet use, and cell phone/telephone use). Another combination involved spending equal amounts of time $(2 \mathrm{~h})$ on each of the five activities. Finally, the last combination involved spending more time on socialization $(4 \mathrm{~h})$, with the remaining time spread across the other four activities (either 1 or $2 \mathrm{~h}$ was specified for each).

Study 1 Results, Phase 2

Although the most popular resource in Phase 1 was social time, respondents in Phase 2 did not want to spend all of their time on this highly-desired activity. The mean desirability ratings in Phase 2, shown in Table 2, reveal that spending all $10 \mathrm{~h}$ on social time was not perceived as most desirable, which is similar to the Phase 1 findings based on a difference form of measurement. Instead, having a mix of all five activities was the most attractive, especially if one could spend more time on the favored activity (social time) rather than spend equal time on each activity. Thus, some balance, but not complete balance, was the most desired, as it enabled people to enjoy a variety of pursuits, but still have more of their favorite activity. Spending all $10 \mathrm{~h}$ on the Internet or talking on a cell phone/telephone was viewed as undesirable. Spending time on a mix of activities was more enjoyable than spending time only in a very favored activity. These findings converged with the results from Phase 1: having a lot of a very good thing is not necessarily the best alternative, and for certain pleasant activities and resources too much may even lead to negative utility and become undesirable.

\section{Discussion Study 1}

Phase 1 of Study 1 has the advantage that all respondents were exposed to all values of the resources, including a wide range of values of those resources. Phase 2 of Study 1 complemented the first phase in that a very different method of measuring utility was used, which did not require respondents to use life years, but instead asked for straightforward desirability ratings of various combinations of activities. However, Study 1 had certain shortcomings that were overcome in Study 2. First, while Study 1 employed only college student respondents, Study 2 relied on a representative sample of the entire world. Second, while Study 1 relied on responses

Table 2 Mean desirability and standard deviations for each combination of activities in Phase 2 study

\begin{tabular}{llr}
\hline Combination of activities & Mean desirability & SD \\
\hline All 10 h on cell phone and telephone & $2.23_{\mathrm{a}}$ & 1.73 \\
All $10 \mathrm{~h}$ on internet & $2.40_{\mathrm{a}}$ & 1.75 \\
All $10 \mathrm{~h}$ socializing & $5.56_{\mathrm{b}}$ & 2.18 \\
$2 \mathrm{~h}$ in each of five activities & $6.74_{\mathrm{c}}$ & 1.67 \\
Mix of the 5 activities (4 h on social time) & $7.82_{\mathrm{d}}$ & 1.37 \\
\hline
\end{tabular}

Ratings covered range from 1 to 9 , and therefore the neutral midpoint of the scale was 5 . The five activities were: telephone, socializing, Internet \& games, exercise and viewing sports, and watching TV/ movies and reading. Means with different subscripts differ by $p<.001$ with Bonferroni correction applied 
to hypothetical situations, Study 2 used people's actual emotions reactions and activities in their daily lives. Finally, in Study 2 we employed yet a third measure of utility. While Study 1 exposed subjects to a wide range of values of resources, including some that would be unlikely in many lives, Study 2 analyzed the value of resources as they naturally occurred in people's lives, and therefore presents an ecologically valid picture of the impact of resources. Finally, while Study 1 measured utility in terms of life years, in Study 2 we employed a very different measure of utility in terms of experienced feelings. We used in Study 2 a measure of "affect balance" (positive minus negative affect) during the previous day, and the amount of time spent in certain pleasant and unpleasant activities yesterday was also assessed. For income, we examined DMU in reference to positive feelings, negative feelings, life satisfaction, job satisfaction, and satisfaction with standard of living. To the best of our knowledge, this is the first time that the DMU of income has been analyzed in reference to such diverse measures of "utility." Thus, Study 2 had several desirable features that complemented Study 1.

\section{Study 2}

The first wave of the Gallup World Poll was conducted in over 130 nations during 2005-2006, with representative samples of over 1,000 respondents in each nation. The poll surveyed respondents in nations that include $96 \%$ of the world's population. In wealthy nations the survey was administered by telephone, whereas in the majority of nations it was conducted with door-to-door interviews. The World Poll has the advantage over earlier surveys in that many poor nations were surveyed, and rural areas were sampled rather than only respondents in major cities.

As part of the survey, respondents were asked about their feelings yesterday, as well as the amount of time spent in various activities yesterday. We selected three activities where time in hours and minutes was reported, and where prior research has shown the activity to be on average pleasant or unpleasant. The survey asked respondents how many hours they had spent with family and friends on the previous day, varying from zero to 24. Kahneman et al. (2004) found that socializing with family and friends is one of the most pleasant activities of the day, and Pavot et al. (1990) found that people report more positive moods during social time than during time spent alone. The second activity was "free time," and again the answers could vary from zero to $24 \mathrm{~h}$. Finally, commuting time to work was reported in minutes, and this was used because it tends to be a less pleasant activity, and therefore provides an alternative look at DMU. Kahneman et al. (2004) found less pleasant moods during commutes to and from work compared to most other activities they examined. For a review of the negative effects of commuting on moods and life satisfaction, see Diener et al. (2009). For each of the three activities we aggregated the responses into categories in order to achieve adequate sample sizes for each category. For example, no free time was coded a "1," while 17-24 h of free time was coded as a "5." In the study we also examined the declining marginal value of household income.

Affect on the previous day was based on the mean of two positive items ("Enjoyment" and "Smiling and laughing") minus the mean of four negative items 
("Depression," "Anger," "Sadness," and "Worry"). For each item respondents were asked whether they felt it much yesterday, and responded "yes" or "no." The Affect Balance score represented the likelihood that a respondent experienced much positive feelings on the previous day minus the likelihood that he or she experienced much unpleasant feelings. Thus, "utility" was assessed in Study 2 as the presence of positive feelings and the absence of negative feelings.

We also examined people's satisfaction with their standard of living as a measure of utility related to income. Respondents were asked whether they were satisfied with their standard of living and responded with "yes" or "no," which was coded as a 1 or 0 . Thus, the category average represents the percent of people in that category who are satisfied with their standard of living. Respondents also reported life satisfaction on Cantril's (1965) 0-10 Ladder scale, where 0 is the worst possible life one can imagine for oneself and 10 is the ideal life one can imagine for oneself. For income we analyzed affect balance, life satisfaction, and satisfaction with standard of living.

\section{Results}

Table 3 shows the Affect Balance scores associated with the levels of time spent in each of the three activities. As can be seen, affect balance in general rose as the two positive activities increased and as commuting decreased. The difference between the five levels was significant in all three activities $(F(4,87550)=159.2, p<.001$; $F(4,88671)=234.6, p<.001 ; F(4,52318)=23.2, p<.001)$. Multiple comparisons (Bonferroni t's) were used to compare the specific levels of the activities. For Free Time, Category 1 differed from the others at $p<.001$, but none of the other categories differed significantly. For Time with Family and Friends categories differed significantly from each other at $p<.001$, except that Categories 2 and 5 did not differ and Categories 3 and 4 did not differ. Again, the general conclusion is that what matters most is having some hours with family and friends, but there is not a steady increase in utility after that. Furthermore, the highest level of contact with family and friends during virtually the entire waking day was associated with lower Affect Balance than the two preceding categories.

Table 3 Affect balance and amount of time spent in activities

\begin{tabular}{|c|c|c|c|c|c|c|}
\hline \multirow[t]{2}{*}{ Time category } & \multicolumn{2}{|l|}{ Free time } & \multicolumn{2}{|c|}{ Time with family $\&$ friends } & \multicolumn{2}{|c|}{ Commuting time } \\
\hline & $\begin{array}{l}\text { Affect } \\
\text { balance }\end{array}$ & $\begin{array}{l}\text { Mean time } \\
\text { hours }\end{array}$ & $\begin{array}{l}\text { Affect } \\
\text { balance }\end{array}$ & $\begin{array}{l}\text { Mean time } \\
\text { hours }\end{array}$ & $\begin{array}{l}\text { Affect } \\
\text { balance }\end{array}$ & $\begin{array}{l}\text { Mean time } \\
\text { minutes }\end{array}$ \\
\hline 1 & $.33(.61)$ & $0(0.0)$ & $.30(.61)$ & $0(0.0)$ & $.55(.52)$ & $0(0.0)$ \\
\hline 2 & $.51(.55)$ & $2.4(1.04)$ & $.48(.56)$ & $2.7(1.05)$ & $.54(.53)$ & $6.7(3.2)$ \\
\hline 3 & $.52(.55)$ & $6.1(1.13)$ & $.55(.54)$ & $6.2(1.13)$ & $.53(.53)$ & $22.5(6.3)$ \\
\hline 4 & $.52(.57)$ & $11.5(1.98)$ & $.55(.55)$ & $11.5(1.93)$ & $.49(.55)$ & $65.6(24.6)$ \\
\hline 5 & $.51(.59)$ & $22.4(2.52)$ & $.50(.58)$ & $21.6(2.63)$ & $.42(.57)$ & $192.7(87.6)$ \\
\hline
\end{tabular}

For free time and time with family and friends, the Categories were: 1 was no time, 2 was 1 to 4 h, 3 was 5 to $8 \mathrm{~h}, 4$ was 9 to $16 \mathrm{~h}$, and 5 was $17 \mathrm{~h}$ and above. For commuting time categories, 5 was none, 4 was 1 to $10 \mathrm{~min}, 3$ was 11 to $30 \mathrm{~min}, 2$ was 31 to $120 \mathrm{~min}$, and 1 was above $2 \mathrm{~h}$ 
Table 4 Income and affect balance

\begin{tabular}{llllllr}
\hline $\begin{array}{l}\text { Income } \\
\text { category }\end{array}$ & $\begin{array}{l}\text { Mean } \\
\text { affect balance }\end{array}$ & $\begin{array}{l}\text { S.D. of } \\
\text { affect } \\
\text { balance }\end{array}$ & $\begin{array}{l}\text { Mean } \\
\text { satisfaction } \\
\text { standard of living }\end{array}$ & $\begin{array}{l}\text { S.D. satisfaction } \\
\text { standard of } \\
\text { living }\end{array}$ & $\begin{array}{l}\text { Mean income } \\
\text { in U.S. } \\
\text { dollars }\end{array}$ & $\begin{array}{l}\text { N for } \\
\text { affect } \\
\text { balance }\end{array}$ \\
\hline 1 & .33 & .62 & .37 & .48 & 492 & 7,726 \\
2 & .45 & .58 & .49 & .50 & 4,685 & 47,251 \\
3 & .53 & .54 & .66 & .47 & 14,718 & 17,267 \\
4 & .60 & .50 & .79 & .41 & 24,316 & 7,384 \\
5 & .60 & .50 & .80 & .40 & 33,808 & 4,588 \\
6 & .63 & .47 & .85 & .36 & 43,874 & 3,116 \\
7 & .66 & .45 & .87 & .34 & 55,281 & 1,992 \\
8 & .64 & .45 & .90 & .31 & 64,961 & 1,655 \\
9 & .67 & .44 & .86 & .34 & 74,357 & 518 \\
10 & .65 & .46 & .92 & .27 & 83,738 & 612 \\
11 & .61 & .46 & .94 & .23 & 95,370 & 652 \\
12 & .68 & .43 & .92 & .27 & 148,869 & 991 \\
\hline
\end{tabular}

Income categories were: $1=0-1000,2=1,001-10,000,3=10,001-20,000,4=20,001-30,000,5=30,001-$ $40,000,6=40,001-50,000,7=50,001-60,000,8=60,001-70,000,9=70,001-80,000,10=80,001-90,000$, $11=90,001-100,000,12=$ above 100,000

For Commuting Time the highest time did not differ from the other levels, due to a much smaller $\mathrm{N}$ than other categories. However, Category 4 differed significantly from the lower three categories, $p<.001$, and Category 2 was significantly lower than Category 3 , $p<.001$, owing to the extremely large N's in these groups and the fact that the difference was almost two points (but appears smaller in the table, due to rounding). Our analysis suggests that some commuting time, below $30 \mathrm{~min}$ to work, was not particularly detrimental to the day's mood, but longer amounts were detrimental, with long commutes being very detrimental. However, even very long commutes were not as detrimental as zero free time or zero time with family and friends $(p<.001)$.

Table 4 shows the Affect Balance of individuals with 12 levels of income, and these categories differed significantly overall $(F(11,93740)=206.5, p<.001)$. The first 3 categories differed at $p<.001$ from all other income categories. Categories 4 and 5 differed at $p<.001$ from categories 7 and 12. Categories 6 through 12 did not differ significantly from each other. Thus, there was a large and steady increase in Affect Balance as income increased up to about $\$ 25,000$, a lesser increase in Affect Balance to about $\$ 50,000$, and then no predictable increase after that.

Figure 1 shows the DMU pattern for income. As can be seen in Fig. 1, there is a steep rise in the various forms of well-being when income increases from very low levels, but only small increases after a moderate level of income are reached.

\section{Discussion}

The findings of Study 2 are consistent with those of Study 1. Not only was there a pattern in declining utility for each of the activities and for income, but there 


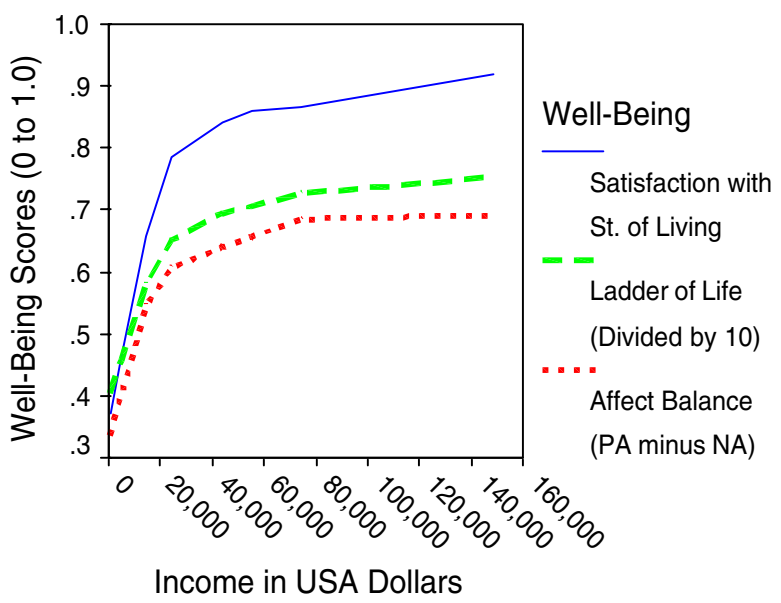

Fig. 1 Gallup World Poll: declining marginal utility of income

appeared to be little or no increase in utility after some point. Not only did increasing units of an activity have less impact, but usually at higher levels they had little benefit at all. In the case of time with family and friends, the highest amount was less desirable than the two preceding levels, repeating the optimal level findings from Study 1. As in Study 1, gaining a relatively small amount of each resource was associated with substantially more utility compared to none of the resource.

It is striking how similar the findings were across very different measures of utility-life years, desirability ratings, affect balance, and satisfaction with standard of living and life. Using very different samples and measures of utility, both studies converged on several conclusions. First, early amounts of a resource are most highly associated with increases in utility. Second, more of a resource after a person has some of it generally has less effect, and sometimes is even associated with lower utility. If one compares across the activities, one gains hints about what tradeoffs might make sense and which might not. For example, giving up an hour a day of commuting to spend more time with family might not increase well-being if family time is already at $8 \mathrm{~h}$ per day, whereas replacing $2 \mathrm{~h}$ of commuting to obtain some free time or family time in a life bereft of those activities could yield huge benefits for well-being.

The methods used in the two studies have complementary strengths. In Study 2, we cannot conclude unequivocally that the associations between affect and the activities are due to engagement in the activities. For example, more materialistic people might commute more, and they could be less happy, with no real effect of commuting. However, this study had the advantage of studying actual activities of a representative sample of the world, and in using experienced affect as the measure of utility. The daily moods measured in the study were not directly linked to each activity, but to the moods of the entire day. However, it is important to note that this should have attenuated the DMU patterns, and therefore our estimates should be conservative regarding the momentary utility of activities, due to the inclusion of other activities during the day. Furthermore, in Study 2 reports of satisfaction with standard of living should have been closely tied to income. In contrast, Phase 1 of 
Study 1 had the strength of obtaining utility figures across all conditions from the same respondents. Therefore, differences in reports of utility, as measured in life years, could not be due to extraneous individual differences, and in Phase 2 of Study 1 we used desirability ratings that assessed various combinations of activities. Although very different methods were used, however, the conclusions from the two studies were virtually identical. Furthermore, the two phases of Study 1 used different methods and led to the same conclusions.

\section{General Discussion}

Replicating the findings of Greene and Baron (2001) and surveys of income and happiness (Diener and Biswas-Diener 2002), we found that income showed a clear pattern of DMU. However, for other goods, the pattern often suggested an ideal or optimal level. It seems possible to have too much of a good thing. Although our respondents wanted children, TV viewing time, social time, and athletic skill, too much of the good was often judged to have less value than a moderate amount. Similarly, in Study 2 people who had some social time with family and friends were substantially happier than those with none, but having too much of this activity was associated with lower affect balance.

A major conclusion of our findings is that people most prefer a mix of activities rather than spending all of their waking moments in a highly pleasurable activity. This conclusion can be drawn from both phases of Study 1, as well as from Study 2. In Phase 1 of Study 1 people reported lower utility for pleasant activities such as socializing and television viewing after a certain optimal point was reached.

Consistent with the pattern of DMU, the ratings of various combinations of activities in Phase 2 of Study 1 suggested that a balance of activities is most desirable. Spending all of one's time on the Internet or telephone was seen as undesirable, and socializing all of the time was seen as only slightly above neutral in desirability. Spreading time across a mix of pleasant activities was rated as more desirable than spending all of one's time in the most desirable activity, socializing. However, the most desirable mix was to have some time for each activity, but more time spent socializing. In Study 2 all three activities and income each showed a DMU pattern, and one that was particularly strong after a moderate level had been achieved. Although the optimal amount of each activity undoubtedly varies across individuals, for the average person there can be too much even of very desirable activities.

In economics DMU is a concept most applied within persons, not in comparing utility across persons. Our findings do cast some light on this issue in showing that in Study 1 different people not only showed different levels of utility for socializing, but reported a different pattern of declining utility for it. Those who spent a lot of time socializing showed very little decline in utility up to the maximum value of $8 \mathrm{~h}$, whereas those who spent less time socializing reached a peak utility at $2 \mathrm{~h}$ per day. Thus, there will be individual differences in where people obtain the optimal level of an activity for them.

Can people obtain greater happiness by switching some of their time to more pleasurable activities? The present findings suggest that a subtle analysis is required 
to answer this question. Simply spending more time in those activities that are highly pleasurable when they are first encountered will not inevitably increase happiness. One must also determine where the person stands on the utility function of each of the activities, before deciding when a tradeoff will be worthwhile. Future research should explore the degree to which people recognize this in their decisions. Another question for future research is the degree to which flexible time is spent in the best mix of activities to produce the most on-line feelings of utility. Thus, we extend the reasoning of Kahneman et al. (2004), as well as Lyubomirsky (2007), in suggesting that time-use reallocation can lead to greater happiness, but with the added caution that people must also consider whether they already spend enough time in certain very pleasurable activities.

One issue is whether our measure of utility in Study 1, life-years, is itself subject to DMU. Greene and Baron (2001) found that life expectancy showed DMU, with earlier years having more value than later years. Does this represent a threat to our study, because we used life-years as the measure of utility? We believe that the DMU of life-years means that our findings are conservative relative to the ideal-point findings, and that the patterns we found would be more pronounced if we had used an equal-interval measure of utility.

If life-years decrease in utility as one moves up the lifespan, which is intuitively plausible and suggested by Greene and Baron's findings, the smaller number of years sacrificed in some conditions would be worth less than the years given up in the conditions where respondents were willing to sacrifice more years because more valuable younger years would be sacrificed in the latter case. For example, giving up the years from 80 to 90 , a 10 -year sacrifice, would be much less than giving up the years that go from 30 to 40 . Our conclusion is that the findings for ideal-points could have been more pronounced. Future research could employ other measures of utility such as standard gambles, or calibrating outcomes in terms of money or other goods and determining whether the same patterns emerge. Our findings suggest, however, that even more extreme ideal-points might be found if an unbiased measure of utility were used.

As some of the first studies of declining marginal utility in goods other than income and consumer products, they raise a number of interesting avenues for future research. For one, researchers should explore the degree to which our findings generalize across a greater range of activities and levels of those activities. For instance, for watching television and socializing $8 \mathrm{~h}$ per day was the maximal amount possible, and researchers could explore the value of even more time in these activities, such as $16 \mathrm{~h}$ per day. Future research should also explore how DMU is influenced by different types of personal characteristics.

Another future line of research is to explore the theoretical reason why DMU occurs? The idea of DMU follows from the power laws of stimulus intensity discovered by the pioneers of psychological research such as Weber, Fechner, and Stevens, which assert that stimuli have effects on people that increase only as the stimulus increases exponentially. Hedonic stimuli might also require greater amounts of intensity to have the same effects on people as one gains more of the resource in question. For example, an income change from 10,000 dollars a year to 12,000 might be very positive, whereas an income change from 100,000 to $102,000 \mathrm{might}$ not be. However, an income change from 100,000 to 120,000 might produce a 
noticeable boost. Another possible explanation for DMU is that people first obtain the goods and activities they most want, and hence receive the most pleasure, and then turn to goods they want less. Thus, additional social time and so forth is less desirable than the first social time one obtains because the first hours are most likely to be spent with the most enjoyable people and in the most enjoyable activities. A third potential reason for DMU is satiation. Some activities are based on physical needs. Once this need is met, they may lose value or even become aversive. Similarly, activity reward might be based on psychological needs, and a balance that meets these needs might be optimal (Sheldon and Niemiec 2006; Sirgy and Wu 2009). A related reason for DMU is boredom. Thus, a variety of mechanisms may underlie DMU, and testing theories that explain DMU is an important avenue for future research. We have established here that DMU is widespread in many hedonic realms, including social activities, and future work should be devoted to a deeper theoretical understanding of this phenomenon. It might be that several different psychological processes are simultaneously at work. However, based on the idealpoint findings for many activities, it appears that satiation and boredom is likely to be involved for at least some cases of DMU.

Declining marginal utility has been frequently discussed by economists, but is a phenomenon that needs to be studied psychologically in more depth across activities and various types of resources. We will then be able to give people sound advice about how best to allocate or reallocate their time to achieve the most utility. However, based on the current findings it seems that a balance of activities is most likely to enhance well-being. Because there are diverse human needs, for most people including diversity in activities is a better route to happiness than simply "putting all of one's eggs in one basket." People are better protected against catastrophic loss if they do not rely completely on only one source for rewards, and they are less likely to become satiated or bored.

What are the applied implications of our findings? In the work arena we suggest that a balance between hours of work, social time, and leisure will produce the highest well-being, whereas even work that is enjoyable will produce less well-being if carried out for too many hours. Conversely, it would be an error to assume that people would be happiest if all of their time were spent in pleasurable leisure activities. What quality of life coaches should do is make clear to clients that the optimal mix of activities requires balance, and help them explore what the best division of time and activities is for them. At the policy level, an implication is that too many work hours, without sufficient free time or vacation, will prove less rewarding for most people. At the personal level, individuals need to understand the importance of balance so that they do not blindly pursue either unlimited income through too many work hours, or unending leisure hours. Our findings help explain why balance in life is a wise course in the pursuit of happiness, although the optimal mix of activities will likely vary from person to person.

\section{References}

Becker, G. S. (1965). A theory of the allocation of time. The Economic Journal, 75, 493-517. doi:10.2307/2228949. 
Cantril, H. (1965). The patterns of human concern. New Brunswick, N.J.: Rutgers University Press.

Cartwright, A. (2007). How does your sex life compare to the rest of the world? Study shows Americans have sex 85 times a year. Associated Content. Retrieved from http:/www.associatedcontent.com/ article/220912/how_does_your_sex_life_compare_to_the.html

Diener, E., \& Biswas-Diener, R. (2002). Will money increase subjective well-being? Social Indicators Research, 57, 119-169. doi:10.1023/A:1014411319119.

Diener, E., Lucas, R., Schimmack, U., \& Helliwell, J. (2009). Well-being for public policy. Oxford, U.K.: Oxford University Publishing.

Greene, J., \& Baron, J. (2001). Intuitions about declining marginal utility. Journal of Behavioral Decision Making, 14, 243-255. doi:10.1002/bdm.375.

Kahneman, D., Krueger, A. B., Schkade, D. A., Schwarz, N., \& Stone, A. A. (2004). A survey method for characterizing daily life experience: the day reconstruction method. Science, 306, 1776-1780. doi:10.1126/science.1103572.

Layard, R. (2005). Happiness: Lessons from a new science. New York: Penguin.

Lyubomirsky, S. (2007). The how of happiness: A scientific approach to getting the life you want. New York: Penguin.

Pavot, W., Diener, E., \& Fujita, F. (1990). Extraversion and happiness. Personality and Individual Differences, 11, 1299-1306. doi:10.1016/0191-8869(90)90157-M.

Sheldon, K. M., \& Niemiec, C. P. (2006). It's not just the amount that counts: Balanced need satisfaction also affects well-being. Journal of Personality and Social Psychology, 91(2), 331-341. doi:10.1037/ 0022-3514.91.2.331.

Sirgy, M. J., \& Wu, J. (2009). The pleasant life, the engaged life, and the meaningful life: what about the balanced life? Journal of Happiness Studies, 10, 183-196. doi:10.1007/s10902-007-9074-1.

Smith, T.W. (2006). American sexual behavior: Trends, socio-demographic differences, and risk behavior (GSS Topical Report No. 25). Retrieved from National Opinion Research Center: http://www.norc. org/NR/rdonlyres/2663F09F-2E74-436E-AC81-6FFBF288E183/0/AmericanSexualBehavior2006.pdf 